\title{
Learning Organization Culture Among Head Nurses at Different Health Care Sectors in Assiut City
}

\author{
Aliaa Rabiea Elhoseney ${ }^{1}$, Samah Mohamed Abdalla ${ }^{2}$ \& Amal Sayed Mohamed ${ }^{3}$. \\ 1. Bachelor degree in nursing science, Assiut Police Hospital, Egypt, \\ 2. Professor of Nursing Administration, Dean of Faculty of Nursing Assiut University, Egypt, \\ 3. Lecturer of Nursing Administration, Faculty of Nursing Assiut University, Egypt.
}

\begin{abstract}
Background: Learning organization culture is one of hospitals principals in which leaders encourage active learning activities. Aim: assess learning organization culture among head nurses. Setting: different health care sectors in Assiut city. Subject and method: 105 head nurses were participated. Tool: questionnaire sheet were used, which includes two parts: Personal data sheet and dimensions of learning organization questionnaire. Results: more than half of head nurses are married and aged less than or equal 30 years $(58.1 \%, 56.2 \%)$ respectively. The majority of head nurses are females having bachelor degree in nursing science (97.1, and 84.8\%). Assiut University Main Hospital head nurses have the highest mean scores regarding all domains of learning organization culture followed by El Mabaraa Hospital head nurses while El Shamla Hospital head nurses has the lowest mean scores. Conclusion: there is statistical significant difference between the three hospitals as regards all domains of learning organization culture. Recommendations: implement policies and training programs to improve learning organization culture, and new researches should be done to test the factors affecting the learning organization culture at different health care sectors in Assiut city.
\end{abstract}

\section{Keywords: Head Nurses, Learning Organization, Culture \& Health Care Sectors.}

\section{Introduction}

Head nurses' role is seen as the hardest role in healthcare system. Head nurses play a critical management role because they can influence the success of healthcare organizations, especially at the unit level. Their role is essential in the development and retention of the staffs and in the responsibility to assure the mission of the facility translated into everyday practice. Head nurse is defined as a registered nurse having 24 hours accountability for the management of a unit(s) or area(s) within a healthcare institution. The term First-line nurse manager has been used interchangeably in the literature with the terms head nurse, ward manager, nursing unit manager, and ward leader. The role of head nurses is divided to management of operation (managerial focus), and management of nursing care (clinical focus) also head nurses have many roles at the unit level and enhance learning to create the basic stone of learning organization culture (Gunawan \& Aungsuroch, 2017).

Learning is defined as change in human behavior resulting from practice and repetition. Also, learning is expressed as change in the ability for responding to the demands of the task or environmental pressure using different and innovative methods, as a result of more quickly respond to same task, or as results of other related interventions. Generally learning involves knowledge gaining, knowledge sharing and knowledge utilization (Gumusluoglu \& ILsev, 2009).

Learning in organization is the main key and requirement factor for organizations that wants to remain in the economic modern world and competitive environment. Thus, organizations must prepare people through learning constantly to deal with changes and to have the ability to adapt with changing conditions and modern challenges and must be able to institutionalize learning within the organization. Learning organizations are strong and powerful organizations because its determinants for success are based on learning (Gilaninia et al., 2014).

Learning organization is one of the hospitals' core values. Leaders in hospitals have to encourage active learning activities for individuals and groups, and have to try to reshape their hospital into learning organization. Nurses are the major workforce in hospitals and play a key role in this transformation. Effective management of nursing organization could add a competitive edge to a hospital's prestige in the globalization world (Chan et al., 2014).

There are different models or characteristics of learning organization which measure organization type that either it is a learning organization or not? Learning organization is one which facilitates learning activity for all members. Researchers have attempted to identify the specifics components and variables which are associated with learning 
organization and they developed different models and several studies which attempted to identify the specific components or dimension of learning organization (Farrukh, 2015).

There are five principles (disciplines) of learning organization described them as follows: Mental Models: are deeply embedded assumptions or images that influence how people understand the world and how people take action. It means people put aside their old ways of thinking, Personal Mastery: Learn to be open with others, clarifying personal vision, focusing on energies, developing patience and seeing reality objectively, System thinking: based on system dynamics, highly conceptual and provide ways of understanding issues, Shared Vision: is a form or a plan everyone can agree on. It is "pictures of the future and Team Learning: means work and thinking together to achieve that vision (Park, 2008). learning organization culture has seven dimensions as follows; Create continuous learning opportunities, Promote inquiry and dialogue, Encourage collaboration and team learning, Establish systems to capture and share learning, Empower people toward a collective vision, Connect the organization to its environment and Use leaders as role model and support the learning of the individual, team, and organizational levels (Marsick \&Watkins, 2003).

\section{Significance of the study}

Much has appeared in professional articles and journals regarding the importance of learning organization. Some had found that learning organization has great impact on adapting and coping with the environmental challenges. Others found that, learning organization enable the workers to be committed with the learning process that encourages experimentation, sets open communication, dialogue and continuous learning towards the achievement of excellence. Health care literature is focusing on organizational learning only for teaching and professional development with little studies in this regard in hospitals.

In Egypt as in many other countries, the administration of healthcare services is a challenge for head nurses managers. The variables of learning organization are not well studied among Egyptian nurses. However, exploring those variables would improve the quality of healthcare services. Thus, this study raises the question of to what extent and how learning organization is accepted, appreciated and practiced at different health care sectors in Assiut city. So researcher intended to study organizational learning capabilities among head nurses at different health care sectors.

\section{Aim of the study}

This study aimed to assess the culture of learning organization at different health care sectors in Assiut city.

Research question

Q: what are the levels of the learning organization culture among head nurses in different health care sectors at Assiut city?

\section{Subject \& Method \\ Technical design}

a) Study design: Descriptive design was used in the present study.

b) Setting: This study was conducted at different health care sectors in Assiut city namely: Assiut University Main Hospital, El Mabara Hospital (health insurance hospital) and El Shamla Hospital (ministry of health and population hospital).

c) Subjects: Convenient sample was used total number of head nurses no. $=(105)$. The study subjects consist of head nurses works in Assiut University Main Hospital (no. =35), El Mabara Hospital (no. =35) and El Shamla Hospital (no. =35). The study subjects were chosen randomly from the head nurses schedule. The research took the first, the third, the fifth and etc... until reach to the number 35 head nurses from each hospital as this number is the total number of head nurses at El Shamla Hospital so the researcher take equal number from Main Assiut University and El Mabara hospitals .

Data collection Tools

The data needed for the study was collected using interview questionnaire sheet which compromised two parts. $1^{\text {st }}$ part personal data sheet: It was designed to collect data about head nurses' age, gender, educational qualifications, years of experience, and hospital name.

$2^{\text {nd }}$ part The Dimensions of Learning Organization Questionnaire (DLOQ): It was developed by Marsick and Watkins, which designed to measure learning organization culture and intends to capture the employee's perception regarding the seven dimensions of learning organization (Marsick \& Watkins, 2003). The seven dimensions of learning organization namely are: 1) Create continuous learning opportunities (3 items), 2) Promote inquiry and dialogue (3 items), 3) Encourage collaboration and team learning (3 items) 4) Create system to capture and share learning (3 items), 5) Empower people toward a collective vision (3 items), 6) Connect the organization to its environment ( 3 items) and 7) Provide strategic leadership for learning (3 items). 


\section{Scoring System}

The seven dimensions of learning organization covered by 21 items with a total score of 63 points head nurse's responses were measured by using three points Likert scale ranging from $1=$ disagree to $3=$ agree. The perception of learning organization culture is considered low with a score less than 38 , while it is considered high with a score equal to or more than 38.

\section{Administrative design}

An official approval to carry out the study was obtained from the responsible persons (hospitals directors, directors of nursing, and all departmental heads in which the study was conducted) in the three selected hospitals participating in this study in Assiut city for the permission to collect the necessary data for the present study.

\section{Ethical Consideration}

The study was conducted with careful attention to ethical standards of research and rights of the participants. The study proposal took an approval from Ethical committee in the faculty of nursing, Assiut University. Oral agreement was taken from all study participants who included in the present study. The study was followed common ethical principles in research. The anonymity and confidentiality of response, voluntary participation and right to refuse / participate and withdraw from the study was emphasized to all participants.

\section{Operational design}

Which includes; preparatory phase, pilot study and field work.

\section{Preparatory phase}

This phase took about 8 months. After reviewing the available literature concerning the study topic, structured self-administered questionnaire has been developed to determine the learning organization culture among head nurses. Study tools were checked for face validity by experts' opinions ( two professors and three assistant professors works at Nursing Administration Department) to test comprehension of each statement then content validity were measured using confirmatory factor analyses and it's result more than 1.8 for all items of study tools so all items were confirmed.

\section{Pilot study}

To determine time needed to fill questionnaire form and to detect any obstacles that may encounter during data collection phase. It done on $10 \%$ of head nurses at the three selected hospitals (no. = 11). The head nurses included in the pilot study were excluded from the total study subjects. No modifications were done after pilot study.

\section{Reliability}

was measured using Cronbach's Alpha Coefficients methods to ensure internal consistency and its results revealed that all statements of study questionnaire $\alpha$ were $\geq 0.85$ for each items of dimensions of learning organization questionnaire.

\section{Field work}

After making necessary modifications in the study tools, the actual data collection from head nurse was started; the researcher met with each head nurse participated in the study to explain the purpose of the study and to ask for participation. Data collection was done by the investigator through personal interview to fill questionnaire form. All data collection information was collected during morning shift, thus each head nurse was personally interviewed one at a time, and each interview took about 40 minutes. The whole duration for data collection took about 6 months.

\section{Statistical design}

Data entry and statistical analysis were done using SPSS v.g 24 program Statistical Soft Ware Package for social science. Data were presented using descriptive statistics in the form of frequencies, percentages, mean and standard deviation. Pearson correlation coefficients were used for assessment of the inter-relations among quantitative variables. For multiple group comparison of quantitative data, one way analysis of variance test (ANOVA) was used. Statistical significance was considered at $\mathrm{P}$-value $\leq$ 0.05 . 


\section{Results}

Table (1): Distribution of head nurses' personal characteristics in different healthcare sectors in Assiut city (no. =105).

\begin{tabular}{|c|c|c|}
\hline Personal Characteristics & No. (105) & $\%$ \\
\hline \multicolumn{3}{|l|}{ Hospital: } \\
\hline Assiut University Main Hospital & 35 & 33.33 \\
\hline El Mabaraa & 35 & 33.33 \\
\hline El Shamla & 35 & 33.33 \\
\hline \multicolumn{3}{|l|}{ Age: (years) } \\
\hline$\leq 30$ years & 59 & 56.2 \\
\hline$>30$ years & 46 & 43.8 \\
\hline Mean \pm SD (Range) & \multicolumn{2}{|c|}{$30.74 \pm 5.10(23.0-47.0)$} \\
\hline \multicolumn{3}{|l|}{ Gender: } \\
\hline Male & 3 & 2.9 \\
\hline Female & 102 & 97.1 \\
\hline \multicolumn{3}{|l|}{ Education level: } \\
\hline Bachelor of Nursing & 89 & 84.8 \\
\hline Postgraduate & 16 & 15.2 \\
\hline \multicolumn{3}{|l|}{ Marital status: } \\
\hline Single & 44 & 41.9 \\
\hline Ever Married & 61 & 58.1 \\
\hline \multicolumn{3}{|l|}{ Years of experience: } \\
\hline$<5$ & 34 & 32.4 \\
\hline $5-10$ & 37 & 35.2 \\
\hline$>10$ & 34 & 32.4 \\
\hline Mean \pm SD (Range) & \multicolumn{2}{|c|}{$8.15 \pm 5.29(1.0-25.0)$} \\
\hline
\end{tabular}

Table (2): Learning organization culture mean scores among head nurses in different health care sectors in Assiut city (total no. =105).

\begin{tabular}{|c|c|c|c|c|}
\hline \multirow{3}{*}{$\begin{array}{c}\text { Learning organization culture } \\
\text { domains }\end{array}$} & \multicolumn{3}{|c|}{ Hospital } & \multirow{3}{*}{ P-value } \\
\hline & $\begin{array}{c}\text { Assiut University } \\
\text { Main Hospital no.=35 }\end{array}$ & $\begin{array}{c}\text { El Mabaraa } \\
\text { no.=35 }\end{array}$ & $\begin{array}{c}\text { EI Shamla } \\
\text { no.=35 }\end{array}$ & \\
\hline & Mean \pm SD & Mean \pm SD & Mean \pm SD & \\
\hline Continuous learning & $7.14 \pm 1.73$ & $6.29 \pm 2.11$ & $4.46 \pm 1.09$ & $0.000^{*}$ \\
\hline Inquiry and dialogue & $6.49 \pm 1.87$ & $6.37 \pm 1.88$ & $3.77 \pm 1.21$ & $0.000^{*}$ \\
\hline Team learning & $6.20 \pm 1.97$ & $5.51 \pm 2.03$ & $3.71 \pm 1.23$ & $0.000^{*}$ \\
\hline Embedded system & $7.14 \pm 2.10$ & $5.91 \pm 1.69$ & $3.63 \pm 0.84$ & $0.000^{*}$ \\
\hline Empowerment & $6.03 \pm 1.93$ & $5.11 \pm 2.01$ & $3.63 \pm 1.19$ & $0.000^{*}$ \\
\hline System connection & $7.40 \pm 2.02$ & $6.09 \pm 1.60$ & $3.83 \pm 1.36$ & $0.000^{*}$ \\
\hline Strategic leadership & $6.57 \pm 1.88$ & $5.74 \pm 2.31$ & $3.54 \pm 0.82$ & $0.000^{*}$ \\
\hline $\begin{array}{ll}\text { Learning } & \text { organization } \\
\text { culture "Total" } & \end{array}$ & $46.97 \pm 11.14$ & $42.03 \pm 11.69$ & $26.57 \pm 5.98$ & $0.000^{*}$ \\
\hline
\end{tabular}

Table (3): Head nurses opinions regarding Learning organization culture levels at different health care sectors in Assiut city (no. $=35$ ).

\begin{tabular}{|l|c|c|c|c|c|c|c|}
\hline \multirow{2}{*}{$\begin{array}{c}\text { Levels of learning organization } \\
\text { culture }\end{array}$} & \multicolumn{2}{|c|}{$\begin{array}{c}\text { Assiut University } \\
\text { Main Hospital } \\
(\mathbf{n = 3 5})\end{array}$} & \multicolumn{2}{|c|}{$\begin{array}{c}\text { El Mabaraa } \\
(\mathbf{n = 3 5})\end{array}$} & \multicolumn{2}{|c|}{$\begin{array}{c}\text { El Shamla } \\
(\mathbf{n = 3 5})\end{array}$} & \multirow{2}{*}{ P-value } \\
\cline { 2 - 8 } & No. & $\%$ & No. & \% & No. & \% & \\
\hline Low & 8 & 22.9 & 16 & 45.7 & 34 & 97.1 & \multirow{2}{*}{$0.000 *$} \\
\hline High & 27 & 77.1 & 19 & 54.3 & 1 & 2.9 & \\
\hline
\end{tabular}


Table (4): Correlation between learning organization culture domains and head nurses age at different health care sectors in Assiut city (no=105).

\begin{tabular}{|l|c|c|}
\hline \multirow{2}{*}{\multicolumn{1}{|c|}{ Learning Organization Culture }} & \multicolumn{2}{c|}{ Age (years) } \\
\cline { 2 - 3 } & r-value & P-value \\
\hline Continuous Learning & 0.402 & $0.000^{*}$ \\
\hline Inquiry and Dialogue & 0.304 & $0.002^{*}$ \\
\hline Team Learning & 0.303 & $0.002^{*}$ \\
\hline Embedded System & 0.373 & $0.000^{*}$ \\
\hline Empowerment & 0.303 & $0.002^{*}$ \\
\hline System Connection & 0.346 & $0.000^{*}$ \\
\hline Strategic Leadership & 0.336 & $0.000^{*}$ \\
\hline Learning Organization & 0.382 & $0.000^{*}$ \\
\hline
\end{tabular}

Table (5): Learning organization culture mean score according to head nurses educational qualifications in different health care sectors in Assiut city (no.=105).

\begin{tabular}{|l|c|c|c|}
\hline \multirow{2}{*}{\multicolumn{1}{c}{$\begin{array}{c}\text { Learning Organization Culture } \\
\text { Domains }\end{array}$}} & \multicolumn{2}{c|}{ Education level } & \multirow{2}{*}{ P-value } \\
\cline { 2 - 3 } & $\begin{array}{c}\text { Bachelor degree in } \\
\text { Nursing science }\end{array}$ & Postgraduate & \\
\cline { 2 - 3 } & Mean \pm SD & Mean \pm SD & \\
\hline Continuous Learning & $5.52 \pm 1.83$ & $8.44 \pm 0.96$ & $0.000^{*}$ \\
\hline Inquiry And Dialogue & $5.22 \pm 1.96$ & $7.31 \pm 1.92$ & $0.000^{*}$ \\
\hline Team Learning & $4.79 \pm 1.87$ & $7.13 \pm 1.96$ & $0.000^{*}$ \\
\hline Embedded System & $5.13 \pm 1.92$ & $7.94 \pm 2.05$ & $0.000^{*}$ \\
\hline Empowerment & $4.56 \pm 1.77$ & $6.94 \pm 2.05$ & $0.000^{*}$ \\
\hline System Connection & $5.74 \pm 2.24$ & $8.13 \pm 1.71$ & $0.000^{*}$ \\
\hline Strategic Leadership & $4.89 \pm 2.00$ & $7.50 \pm 1.86$ & $0.000^{*}$ \\
\hline Learning Organization & $35.85 \pm 11.73$ & $53.38 \pm 10.77$ & $0.000^{*}$ \\
\hline
\end{tabular}

Table (6): Correlation matrix between learning organization culture domains with head nurses years of experience (no=105).

\begin{tabular}{|l|c|c|}
\hline \multicolumn{1}{|c|}{$\begin{array}{c}\text { Learning Organization Culture } \\
\text { Domains }\end{array}$} & \multicolumn{2}{c|}{ Years of experience } \\
\cline { 2 - 3 } \multicolumn{1}{c|}{ r-value } & P-value \\
\hline Continuous Learning & 0.429 & $0.000^{*}$ \\
\hline Inquiry and Dialogue & 0.697 & $0.002^{*}$ \\
\hline Team Learning & 0.716 & $0.001^{*}$ \\
\hline Embedded system & 0.698 & $0.000^{*}$ \\
\hline Empowerment & 0.7299 & $0.002^{*}$ \\
\hline System Connection & 0.960 & $0.000^{*}$ \\
\hline Strategic Leadership & 0.846 & $0.000^{*}$ \\
\hline Learning Organization & 0.795 & $0.000^{*}$ \\
\hline
\end{tabular}

Table (1): Reveals that more than half of head nurses are married and aged less than or equal to 30 years $(58.1,56.2 \%)$ respectively. The majority of head nurses are females having bachelor degree in nursing science (97.1, and $84.8 \%$ ), and more than one third of them have experience from 5-10 years (35.2\%).

Table (2): Reveals that Assiut University Main Hospital has the highest mean scores regarding all domains of learning organization culture followed by El Mabaraa Hospital while El Shamla Hospital has the lowest mean scores regarding all domains of learning organization culture. Also there is statistical significant difference between the three selected hospitals as regards all domains of learning organization culture $\mathrm{P}$ value $\leq 0.000$.

Table (3): Depicts that the majority of head nurses works at Assiut University Main Hospital (77.1\%) and more than half of head nurses works at El Mabaraa (54.3\%) mentioned that their organization had high level of learning organization culture but the majority of head nurses works at El Shamla Hospital 
$(97.1 \%)$ mentioned that their organization had low level of learning organization culture.

Table (4): Reveals that there are significant positive correlations between all learning organization culture domains with head nurses age, with statistical significant relation $P$ value $\leq \mathbf{0 . 0 0 0}$.

Table (5): Reveals that head nurses who had postgraduate education had higher mean score than head nurses had only bachelor degree in nursing science as regarding all learning organization culture domains with statistical significant difference $\mathbf{P}$ value $\leq \mathbf{0 . 0 0 0}$.

Table (6): Reveals that there are significant positive correlations between head nurses years of experience and all learning organization culture domains $\mathbf{P}$ value $\leq \mathbf{0 . 0 0}$.

\section{Discussion}

It becomes critical for health care organizations to develop strategies that aim to design new work practices and to manage knowledge. The introduction of learning organization culture is seen as a promising choice for better knowledge management and continuing professional development in health care. The learning organization culture seemed to affect daily nursing work in a positive manner. These changes were particularly pronounced with respect to knowledge transfer, support for nursing practices that reflect quality of health care (Gagnon et al., 2015). Learning Organization is a promising strategy, nurse managers and leaders can use learning organization culture to improve organizational performance. Learning organization culture occurs when experiences are translated into positive changes in the organization's collective knowledge, cognition and actions. Organizational context plays a key role in the learning process. Nurses' managers and leaders can improve patients and organizational outcomes by creating an environment conducive to translating experiences into organizational learning (Lyman et al., 2019).

The present study aimed to assess learning organization culture among head nurses at different health care sectors in Assiut city. To test these aim about 105 head nurse were included in the present study from Assiut University Main Hospital, El Mabara and El Shamla hospitals with equal percent $33.33 \%$, more than half of the selected sample aged from 30 years and more and ever married. The majority of them were females, had bachelor degree in nursing science. More than one third of selected sample had years of experience from 5 to 10 years. The present study findings depicted that Assiut University Main Hospital head nurses had the highest mean scores regarding all domains of learning organization culture followed by El Mabaraa Hospital head nurses while El Shamla Hospital head nurses have the lowest mean scores. Also there is statistically significant difference between head nurses at the three selected hospitals as regarding to all domains of learning organization culture.

These findings are in the same line with (Leufvén et al., 2015) who confirmed that the visible progress detected in one or more dimensions needs to be complemented with equal progress in other dimensions to foster a complete effective learning cycle and obtain the overall capabilities of an advanced learning organization culture.

From the researcher point of view learning organization culture mean scores among head nurses in different health care sectors in Assiut city are heterogeneous, and this is because Assiut University Main Hospital head nurses had a positive tendency to teamwork and good communication skills between them which affect positively the organization members learning desire.

Also present study findings depicted that the order from the highest mean score to the lowest mean score of the seven dimensions of the learning organization culture at Assiut University Main Hospital as follows: system connection, continuous learning, embedded system, inquiry \& dialogue, strategic leadership, team learning and empowerment.

To some extent the findings corroborate with a study done by (Akhtar et al., 2011) which highlighted that system connection achieve the highest mean score among all organizational culture domains and had a greater impact on individual performance which will lead to the overall performance of the organization.

This might be because the head nurses are helped to see the effect of their work on the entire enterprise; head nurses scan the environment and use information to adjust work practices in the organization which in return linked and serve its community. This might be due to the great efforts that the higher managerial levels exert to service the plans of the political government.

There may also be an unwillingness to critique managers and leaders due to the hierarchical structure in the developing countries. Also, This might be due to as continuous learning reflected as opportunities to learn, head nurses perceived prospect for ongoing education and growth as crucial to contribute to overall performance of their job so head nurses do a real efforts to help each other for learning while the hospitals management have to do more efforts to support continuous learning .

On other hand the study findings revealed that the lowest mean score of learning organization culture domains among head nurses at Assiut University Main Hospital is that for empowerment. This result goes in the same line with (Marsick \& Watkins, 2003) as they found that empowerment domain achieve the lowest main score in studying registered 
nurses learning organization culture domains in England.

This result is consistent with studies done by (O'Neil, 2003), (Lien et al., 2006), (Weldy et al., 2010) \& (Awasthy et al., 2011) which concluded that in different settings, a low score on the empowerment dimension has been connected with organizations that display a centralized hierarchical structure, where the lower level employees may have limited access to information and limited authority to make decisions, which leaves little or no motivation to take initiative for learning or incorporation of new ideas.

This finding is also consistent with (Leufvén et al., 2015) who found that the respondents had lowest score in empowerment, indicating a potential area for improvement in health care sector in developing countries. This finding is also goes in the same line with (Neshat et al., 2016) who stated that all the members of the organization need to be more involved in the decision making processes and must identify and overcome the barriers to becoming a learning organization. These results goes in the same line with (Bhattacharya et al., 2017) who found that empowerment came out be the key defining factors for learning organization in hospital and healthcare.

From the findings of the current study, the majority of head nurses works at Assiut University Main Hospital and more than half of head nurses works at El Mabaraa Hospital mentioned that their organization have high level of learning organization culture but the majority of head nurses works at El Shamla Hospital mentioned that their organization have low learning organization culture. Also there is statistically significant difference between the three selected hospitals as regards the level of perception of learning organization culture among head nurses in different health care sectors in Assiut city.

These finding goes in the same line with (Leufvén et al., 2015) who found that the results of her exploratory study provide some evidence of how perceptions of learning organization culture vary across organizational levels and vary in different health care sectors especially in developing countries. This might be due to that in the University hospitals and in health insurance hospitals there are more opportunities for learning and better resources than in ministry of health hospitals.

From the current study results, there are positive correlation between all learning organization culture domains and age. This result goes in the same line with (Nazari et al., 2012) who found that personal data had different perceptions of learning organization dimensions. The age differences in respondents' perception of their college as a learning organization produced significant differences in the seven learning organization dimensions. This might be due to older head nurses have more attention to the importance of continuous learning.

From the current study results, head nurse with post graduate degrees have higher perception for all domains of learning organization culture. Also there is statistically significant difference between head nurses with bachelor degree and head nurses with post graduate degrees in perception of all domains of learning organization culture. It signifies that head nurses with master and doctorate degrees pay more attention to the activities performed regarding learning organization dimensions.

These results are in the same line with (Tseng, 2010) findings who reported that there were significant differences in learning organization practices among respondents with doctorate, master, two year college, senior high school and junior high school degrees, except in system connection dimension in Taiwan.

These results are consistent with (Nazari et al., 2012) who found that in terms of education level, there were significant differences in perception of learning organization dimensions among doctorate, master and bachelor holders. Also in comparison of mean scores of doctorate, master and bachelor holders revealed that doctorate lecturers scored the highest.

From the findings of the current study there is a significant positive correlation between head nurses years of experience and all domains of learning organization culture. This might be as head nurses experience increases their perception to learning organization culture in the hospital increase. These results go in the same line with (Erdem et al., 2014) who found that there were statistical differences at the two dimensions of learning organization, shared vision and team learning in terms of teachers' service period. He argued that experienced teachers having more tendencies to share vision of their schools and team learning than less experienced teachers.

\section{Conclusion}

The present study offer insight into learning organization culture among head nurses at different health care sectors in Assiut city it can be concluded that:

Assiut University Main Hospital(university hospital) has the highest mean scores of all domains of learning organization culture followed by El Mabaraa Hospital(health insurance hospital) while El Shamla Hospital (ministry of health and population hospital) has the lowest mean scores of all domains of learning organization culture. Also, there is statistical significant difference between the three selected hospitals as regards all domains of learning organization culture. 


\section{Recommendations}

Based upon results the following recommendations are drown;

Implement policies to improve levels of learning organization culture.

Ensure a continuous learning culture among head nurses using training programs, knowledge sharing and work team behavior.

New researches should be done to test the factors affecting the learning organization culture at different health care sectors in Assiut city.

\section{References}

1. Akhtar, S., Arif, A., Rubi, E., \& Naveed, S., (2011): Impact of learning on organizational performance: Study of higher education institutes. International Journal of Academic Research, Vol. (3) No. (5), Pp. 327-331.

2. Awasthy, R., \& Gupta, K., (2011): Is learning orientation in manufacturing and service firms different in India? Learn Organ. J, Vol. (18), No. (5), Pp. 392-408.

3. Bhattacharya, S., Neelam, N., Behl, A., \& Acharya, S., (2017): A comparative study of learning organization practices of Indian businesses. Int. J. Learning and Change, Vol. (9), No. (2), pp. 145-149.

4. Chan, P., Chokbunyasit, N., \& Nonglak, I., (2014): Factors affecting the learning organization of Nursing Service Division, Maharaj Nakorn ChiangMai Hospital. Journal of Nursing, Vol. (34), No. (4), Pp. 55-67.

5. Erdem, M., İlğan, A., \& İbrahim, H., (2014): Relationship between Learning Organization and Job Satisfaction of Primary School Teachers. International Online Journal of Educational Sciences, Vol. (6), No. (1), Pp.8-20.

6. Farrukh M., (2015): Learning organization and competitive advantage - An integrated approach. Journal of Asian Business Strategy, Vol. (5), No. (4), Pp. 73-79.

7. Gagnon, B., Jean-Paul, F., Guy, P., José, F., \& Franc, E., (2015): A learning organization in the service of knowledge management among nurses: A case study. International Journal of Information Management, Vol. (35), Pp. 636-642. www.elsevier.com/locate/ijinfomgt

8. Gagnon, M., Fortin, P., Paré, G., \& Côté, J., (2015): A learning organization in the service of knowledge management among nurses: A case study. International Journal of Information Management, Vol. (35), Pp. 636-642. http://dx.doi.org/10.1016/j.ijinfomgt.2015.05.001.

9. Gilaninia, S., Rankouh, M., \& Gildeh, M., (2014): Overview on the importance of organizational learning and learning organization.
Journal of Research and Development, Vol. (1) No. (2), Pp. 44-47.

10. Gumusluoglu, L., \& ILsev, A., (2009): transformational Leadership and organization Innovation: the roles of Internal support for Innovation, Vol (3), No. (2), Pp. 55-58. www.ssrn.com.

11. Gunawan, J., \& Aungsuroch, Y., (2017): Managerial Competence of first- line Nurse Manager: A Concept Analysis, International Journal of Nursing Practice, Vol. (23), No. (1), Pp. 23-29.

12. Leufvén, M., Vitrakoti, R., Bergström, A., Ashish, E., \& Målqvist, M., (2015): Dimensions of Learning Organizations Questionnaire (DLOQ) in a low-resource health care setting in Nepal. Health Research Policy and Systems J, Vol. (6), Pp. 13:6. http://www.health-policysystems.com/content/13/1/6

13. Lien, H., Hung, Y., Yang, B., \& Li, M., (2006): Is the learning organization a valid concept in the Taiwanese context? Int J Manpow, Vol. (27), No. (2), Pp.189-203.

14. Lyman, B., Hammond, E., \& Cox, J., (2019): Organizational learning in hospitals: A concept analysis. J Nurs Manag, Vol. (27) Pp.633-646. https://doi.org/10.1111/jonm.12722

15. Lyman, B., Hammond, L. and Cox, J. (2019): Organizational learning in hospitals: A concept analysis. J Nurs Manag, Vol. (27), Pp. 633-646. https://doi.org/10.1111/jonm.12722.

16. Marsick J., \& Watkins E., (2003): Demonstrating the value of an organization's learning culture: the dimensions of the learning organization questionnaire. Adv Dev Hum Resour journal, Vol. (5), No. (2), Pp.132-51.

17. Nazari, K., \& Pihie, Z., (2012): Assessing Learning Organization Dimensions and Demographic Factors in Technical and Vocational Colleges in Iran. International Journal of Business and Social Science, Vol. (3), No. (3), Pp 23-27. www.ijbssnet.com

18. Neshat, N., Mirhosseini, Z., \& Zahedi, Z., (2016): Becoming a Learning Organization: A Case Study of the National Library and Archive of Iran. Langsam Library, University of Cincinnati J, Vol. (6), No. (6), Pp.13- 5.

19. O'Neil, J., (2003): Participant's guide for interpreting results of the dimensions of the learning organization questionnaire. Adv Dev Hum Resour J, Vol. (5), No. (2), Pp. 222-30.

20. Park, J., (2008): Validation of Senge's learning organization model with teachers of vocational high schools at the Seoul Megalopolis. Asia Pac Educ Rev J, Vol. (9) No. (3), Pp. 270-84. 
21. Tseng, C., (2010): The Effects of Learning Organization Practices on Organizational Commitment and Effectiveness for Small and Medium-Sized Enterprises in Taiwan. Published Doctoral Dissertation The University of Minesota.

22. Weldy, T., \& Gillis, W., (2010): The learning organization: variations at different organizational levels. Learn Organ. J, Vol. (17), No. (5), Pp. 455-70.

23. Yaghoubi, M., Ahmad, R., Mina, A., Mohammad, Y., \& Akbar, H., (2010): The relationship between the learning organization and organizational commitment among nursing managers in educational hospitals of Isfahan University of Medical Sciences in 2008-9. IJNMR, Vol. (15), No. (2), Pp. 78-84. 